\title{
Presence of a predator image in potential breeding sites and oviposition responses of a dengue vector
}

\author{
Hamady Dieng ${ }^{\mathrm{a}}$, Tomomitsu Satho ${ }^{\mathrm{b}}$, Nur Farrahana Binti Suradi ${ }^{\mathrm{c}}$, Hafijah Hakim ${ }^{\mathrm{a}}$, \\ Fatimah Abang ${ }^{\mathrm{c}}$, Nur Ezzati Aliasan ${ }^{\mathrm{a}}$, Fumio Miake ${ }^{\mathrm{b}}$, Wan Fatma Zuharah ${ }^{\mathrm{d}}$, Nur Faeza A. Kassim ${ }^{\mathrm{d}}$, \\ Abdul Hafiz A. Majid ${ }^{\mathrm{d}}$, Nik Fadzly ${ }^{\mathrm{d}}$, Ronald E. Morales Vargas ${ }^{\mathrm{e}, *}$, Noppawan P. Morales ${ }^{\mathrm{f}}$, \\ Gabriel Tonga Noweg ${ }^{\mathrm{a}}$
}

${ }^{a}$ Institute of Biodiversity and Environmental Conservation (IBEC), Universiti Malaysia Sarawak, Kuching, Kota Samarahan, Malaysia

${ }^{\mathrm{b}}$ Faculty of Pharmaceutical Sciences, Fukuoka University, Japan

${ }^{\mathrm{c}}$ Faculty of Resource Science and Technology, Universiti Malaysia Sarawak, Kota Samarahan, Malaysia

d School of Biological Sciences, Universiti Sains Malaysia, Penang, Malaysia

e Department of Medical Entomology, Faculty of Tropical Medicine, Mahidol University, Thailand

${ }^{\mathrm{f}}$ Department of Pharmacology, Faculty of Science, Mahidol University, Thailand

\section{A R T I C L E I N F O}

\section{Keywords:}

Aedes aegypti

Predator

Photo

Oviposition

\begin{abstract}
A B S T R A C T
In dengue vector control, attempts to minimize or replace the use of pesticides have mostly involved use of predators, but success has been severely impeded by difficulties associated with financial and environmental costs, predator mass production, and persistence in target habitats. Visual deterrents have been used successfully to control animal pests, in some cases in an effort to replace pesticide use. Despite evidence that visual signals are crucial in site choice for egg deposition by dengue vectors, and that female mosquitoes respond to artificial predation, the role of predator intimidation as it affects the oviposition behavior of dengue vectors remains largely unexplored. Here, we examined the oviposition responses of Aedes aegypti exposed to various mosquito predator pictures. Gravid females were presented with equal opportunities to oviposit in two cups with predator images [Toxorhynchites splendens_-TXI, Goldfish (Carassius auratus)—small (SFI) and large (LFI) and Tx. splendens + Goldfish-TXFI] and two others without pictures. Differences in egg deposition were examined between sites with and without these images. When given a chance to oviposit in cups with and without TXI, Ae. aegypti females were similarly attracted to both sites. When provided an opportunity to oviposit in cups displaying pictures of fish (SFI or LFI) and blank cups, egg deposition rates were much lower in the fish picture sites. Females showed a preference for blank cups over TXFI for egg deposition. They also equally avoided cups with pictures of fish, regardless of the size of the picture. Our results indicate that the presence of images of goldfish and their association with Tx. larvae significantly reduced egg deposition by Ae. aegypti, and this was not the case with the predatory larvae alone. The observations that the images of natural predators can repel gravid females of a dengue vector provide novel possibilities to develop effective and inexpensive alternative tools to harmful insecticides.
\end{abstract}

\section{Introduction}

The world has experienced unprecedented urban growth in recent decades, which has led to the extinction of many natural predators (McKinney, 2002) and also to the spread of mosquito vectors (WHO, 2014). And the current challenges for suppressing malaria (Benelli and Beier, 2017) are reminders of the unceasing menace associated with mosquitoes. These include, Aedes vectors that spread dengue and Zika disease (Benelli and Mehlhorn, 2016), which are major global public health threats (Hennessey et al., 2016; CDC, 2016; WHO, 2016). Vector control through the use of chemical insecticides was the main strategy for controlling these diseases (WHO/WPR, 2010a, 2010b), but the development of insecticide resistance (Whalon et al., 2008; Naqqash et al., 2016) together with environmental and human health concerns (Stahl, 2002) regarding these agents decreased the utility of this strategy (Karunamoorthi and Sabesan, 2013). In addition, the resulting reduction of the spectrum of effective agents (Dusfour et al., 2011) combined with the absence of effective vaccines and specific therapeutics

\footnotetext{
* Corresponding author.

E-mail address: ronald.mor@mahidol.ac.th (R.E.M. Vargas).
} 